\title{
The Role of Leadership in Policy Implementation: The Case of Selected Federal Public Institutions in Ethiopia
}

\author{
Dereje Terefe Gemechu \\ School of Policy Studies, College of Leadership and Governance, Ethiopian Civil Service University, Addis Ababa, Ethiopia \\ Email address: \\ tedereje002017@gmail.com,dereje_terefegemechu@yahoo.com \\ To cite this article: \\ Dereje Terefe Gemechu. The Role of Leadership in Policy Implementation: The Case of Selected Federal Public Institutions in Ethiopia. \\ International Journal of Science, Technology and Society. Vol. 9, No. 4, 2021, pp. 188-208. doi: 10.11648/j.ijsts.20210904.16
}

Received: June 1, 2021; Accepted: August 3, 2021; Published: August 26, 2021

\begin{abstract}
Scholars believe that there is nothing more omnipresent than public policies in our daily lives, where we are directly or indirectly affected by policy decisions. This leads to the view that almost every aspect of our life is directly regulated through policy decisions, some of which we are often unaware of. Hence, nobody can escape the consequences of public policies wherever they live, in their own country, or elsewhere. In the implementation equation, the role of leadership is considered critical and irreplaceable. But more often than not, such role is either forgotten or mixed up with other stakeholders. The objective of this study is to find out the role of leadership in policy implementation in selected federal public institutions in Ethiopia and come up with possible way- forward suggestions for policymakers. The study used a descriptive-explanatory design with combined research approaches. The findings show that leadership role in policy implementation is decisive and incontestable, while their commitment is not found to the level expected; accountability for implementation deficit is either little or non-existent. Underlying causes were ascribed to lack of meritocracy in leadership recruitment and promotion, absence of spelt-out accountability code of conduct, continuous leadership turnover, and disempowerment of the bureaucracy by the political institution in place. In response, it is recommended that a continuous capacity building plan be executed to raise leaders' knowledge, skills and commitment; apply a merit-based leadership assignment through performance-based evaluation; install accountability code of conduct in public institutions; maintain institutional memory and policy stability by reducing leadership turnover; and relax the decision power of the bureaucracy, particularly at policy implementation side of the scale.
\end{abstract}

Keywords: Public Policy, Policy Implementation, Leadership, Stakeholders, Public Institutions, Federal

\section{The Role of Leadership in Policy Implementation}

\subsection{Introduction}

In the modern world, the concept and practice of public policy is ubiquitous. People are affected directly and indirectly by an extensive array of public policies. To Anderson [1] public policy is a "purposive course of action followed by an actor or set of actors to deal with a problem of concern". Anderson further added that public policies confer advantages and disadvantages; cause pleasure, irritation and pain; but have collective essential consequences for people's well-being and happiness as well. In broader sense, public policy is the study of government actions: "what they do, why they do it, what their actions lead to and to what difference" [2]. Harold Lasswell [3], who is considered the 'father' of policy sciences, relates public policy as "a projected program of goals, values, and practices".

Indeed, what makes public policy so diverse and complex is its conceptualization, formulation and implementation. In it, there are several competing institutions and interest groups who have equally differing value systems to steer policies in the way they wish [4]. One of the most trying components of policy processes is implementation. Knill and Tosun consider implementation as "putting public policy into practice" [5]. Indeed, implementation is a decisive stage of execution of the policy where various actors, organizations, procedures, and techniques work together to put adopted policies into effect to attain program goals [6]. Implementation can also be assumed as a deliverable service; as a process; an output; and an outcome [7]. 
But implementation is not as simple as it may seem at first sight. For instance, some scholars such as George Honadle [8], policy implementation is associated to that of "social carpenters and masons who fail to build to the specifications and thus distort the beautiful blue print". While it may seem straightforward and automatic pursuant to approval, the empirical analysis of policy implementation, however, shows a complex side of the scale. This complexity is contingent as it encompasses various actors- public and private actors, civil societies and the large public- who are directed at the achievement of goals specified in terms of their outputs. In consequence, there is often a substantial gap (also referred to as "missing-link") between the passage of legislation and its application, which is to be addressed by implementation researches.

Policy implementation has to be seen from two main levels. The first is the macro-implementation level that comprises of central actors who initiate policy outputs, i.e., simply putting a policy in place. The second is a microimplementation level where sub-national and local actors react to the macro-level policies and develop their own implementation mechanism and act on it. However, Berman [9] and Matland [10] argue that implementation problems stem from the fact that the macro level cannot fully influence micro-level implementers, leading to a variation in how the same policy initiated at the center is implemented at the local level differently.

One important ingredient in the policy implementation process is the leadership aspect. In the implementation arena, the role of leadership is pervasive and quintessential. For Bekker and Heyningen [11], leadership and policy performance are influenced by the commitment and competences of leaders. Hence, leadership is considered as the external driving force, while commitment and competencies of individual staff members are regarded as the internal forces that enhance successful implementation. To this end, Stogdill [12] describes that an effective leader is characterized by a strong drive for responsibility and task completion, vigor and persistence in pursuit of set goals. According to LaMonte [13], this is done through vision, passion and team skills.

Studies by Hicklin and Godwin [14] reveal that administrative failures are possible explanations for poorly performed implementation outcomes. Consequently, it goes without saying that both scholarly and popular discourse tend to agree that there are substantial variations in the leadership abilities or quality of those who are appointed to head public institutions. In spite of such limitations, however, Hicklin and Godwin argue that many policy scholars are hesitant to include leadership quality as an essential element to determine the quality of policy performance. The assumption that poor leadership can uncover useful points to identify factors affecting implementation would lead to higher quality management as well as policy performance is subject to considerable debates and disagreements. Signe [15], for instance, advances the view that successful implementation of any policy depends not only on full understanding of the policy by all parties involved, but also on appropriate evaluation, commitment, collaboration, both horizontal and vertical, which are to be organized and effectively led by the leadership. Thus, it can be fairly argued, that leadership role is an important predictor for effective policy implementation outcomes.

The objective of this study was, therefore, to find out the attributes of leaders vis-à-vis policy implementation in selected federal public institutions and to generate policy ideas for policymakers and politicians that could contribute to apply critical measurement criteria while assigning leaders to public institutions in the study federal public institutions.

\subsection{Statement of the Problem}

Policy implementation is the process "to actualize, apply and utilize policy in the world of practice" [16]. In fact, the main rationale for having a policy in place is to solve public problems and improve their life styles within the range of what a country can offer to its citizens. Implementation requires the irreplaceable influence, inspiration and empowering of the employees by the leadership to collectively achieve policy goals [17]. Successful implementation is also considered to be the outcome of leaders' competence, commitment and continuity. But for Robichau and Laurence [18], contemporary research reveals implementation as a 'missing-link' in the public policy process.

Consequently, many of the aforementioned scholars argue that policy implementation requires a disposition to take action rather than providing descriptions of what should be done. To Blanchard and Zigarmi [19], it is only the commitment and competence of staff and the leadership which are main prerequisites for the achieving excellence in policy performance.

As any other developing countries, policy implementation process also faces several bottlenecks in Ethiopia. Both policymakers and implementers admit that there is a gap between what is intended and what actually has to get implemented. As a result, lamentations of implementation inefficiencies are often times heard almost in all public conferences, reports to the parliament, as well as at ministerial and institutional levels. While there are apparent and plausible causes for implementation deficits in the country, for Mulugeta [20], Biruk [21], Dereje [22], Tiruye and Dereje [23], skewed stakeholders' participation and the legacy of policy centralization are major policy implementation challenges in Ethiopia, which also implies limited leadership commitment and absence of accountability.

While the leadership, specifically, middle-level leader or leadership, occupies a strategic position in an organization to both follow-up daily implementation routines and also help translate policies and strategies into concrete outcomes, the accountability side of the scale is either glossed over or deliberately ignored. As a result, it is only in the recent rare reports that the subject of lack of leadership commitment and accountability has been officially revealed by the nation's 
Policy Studies and Research Center (PSRC) [24]. But as of recent, the gravity of lack of accountability by the leadership in many of the public institutions in the country has come into spotlight and put under serious scrutiny.

For instance, in a study conducted in two regional states and one city administration, Zerihun and Tesfaye [25] found that the leadership lacks motivation, commitment, and communication of vision and inspiring employees. Moreover, the leaders lack visionary leadership, while their accountability is not clearly spelt-out to the public and themselves. Similarly, in a study conducted in Tigray Regional State, Gebre Mirutse [26] found out that while effective leadership is vital in public institutions, leadership support and commitment has been found poor in the public service reform in the study area. Moreover, to the best of the researcher's knowledge, research accounts on the role of leadership and their accountability to policy implementation failures are either scarce or inaccessible for public scrutiny and research purposes. The motivation of this research, therefore, was found appropriate and timely. The objective of this study is, therefore, to assess the role of leadership in policy implementation success or failure in selected federal public institutions and come up with possible way-forward suggestions.

\subsection{Research Questions}

The following research questions were put forward in order to come up with answers:

1) Are leadership roles distinctively spelt-out to which leaders have to adhere?

2) What is the level of leadership implementation commitment in the study public institutions?

3) To what extent is leadership accountability observed in case of implementation failure?

4) What main factors hamper leaders' commitment to discharge their vested responsibilities?

\subsection{Research Objectives}

\subsubsection{General Objective}

The general objective of this study is to assess the role of leadership in policy implementation and forward possible recommendations to policymakers and other stakeholders.

\subsubsection{Specific Objectives}

The study intended:

1) To identify if there are clearly spelt-out leadership roles to adhere in policy implementation;

2) To find out leadership commitment in policy implementation in study public institutions;

3) To investigate the level of accountability observed upon policy implementation failure; and

4) To distinguish main factors that hamper leaders to discharge their vested responsibilities.

\subsection{Significance of the Study}

The policy subject in general, and policy implementation in the light of leadership role in particular, is both important and timely in Ethiopia. Many government mega projects' implementation reports by mainstream media indicate that they have been either delayed beyond their completion time, or some of them have not even begun operation. In all of such implementation malpractices, the leadership role is always under question. As a result, some of public institution leaders have been sacked for good while reshuffling others. This clearly shows some level of incongruence when it comes to role of leadership and their adherence to institutional norms and observing accountability criteria. In consequence, there is a need for critical investigation of the relationship between policy implementation and that of leadership role so that research hints can be acquired that can guide future policy implementation modalities. It is also hoped that this study will generate possible policy ideas for assigning future policy leaders who have the knowledge and capability to ensure effective implementation outcomes. The study can also contribute to future investigation initiatives in order that policymakers and stakeholders can benefit from the findings and suggestive recommendations.

\subsection{Scope and Limitation of the Study}

Thematically, the study was delimited to investigate the role of leadership in policy implementation. However, this study does not attempt to open the entire Pandora's Box of implementation due mainly to the austerity of time and related resource constraints. It is also geographically delimited to selected federal public institutions which are in charge of continuous policymaking and implementation processes. Some of them were identified with relative better service delivery accounts, while others have been continuously under public scrutiny for delayed projects through parliamentary reports as well as by mainstream media. Others institutions are neither loudly condemned nor appraised publicly and out of media spotlights in most cases.

Consequently, purposively selected federal Ministry of health, Office of the Document Registration and Authentication Authority (DARA), Immigration, Ministry of Labor and social affairs, and Ministry of construction and urban development, have been the focus of the study. The researcher believed that these federal public institutions are in continuous policy implementation and review due to the dynamism of their sector-specific demands. As a result, the findings from these few federal public institutions could only be an eye-opener and cannot be generalized to other federal or state-level institutions as far as policy implementation is concerned. Furthermore, lack of research outputs in this specific study area (leadership versus policy implementation) also makes the study and its findings to be limited. Despite such obvious limitations, however, the researcher has exerted utmost efforts to come up with essential indicative findings. It is believed that the findings can shed at least initial lights on the existing role of leadership in the policy enterprise in general and its implementation in particular. 


\subsection{Operational Definitions of Key Terms Used in the Study}

a) Policy: a decision made by government which entails actions to respond to public demands or problems.

b) Policy implementation: it is one of the policy stages in which government plans and commitment can be put into action.

c) Role of Leadership: refers to the strategic guidance, support, follow-up and passion to realize set goals with the employees who already shared vision and mission of an institution..

d) Middle-level leadership: is the category between top and lower leadership layers but much closer to implementation. They are strategically placed to assess and act on decisions and activities within their domain.

e) Expert: are senior or junior professionals who are on direct implementation lines.

f) Implementation factors: are conditions that facilitate or retard implementation process.

\section{Review of Related Literature}

Public policy is the study of government decisions and actions in order to deal with public concerns. As clearly explained earlier in this article by Dye and associates such as Cochran and Malone [27], public policy is what governments choose to do or not to do. The decisions and actions are directed to achieving desired goals or objectives, which in turn amount to solutions of public problems that are of multidimensional in nature. Consequently, it can be said that public policy is considered as a decision-centric and goaloriented process. A study of public policy is deemed necessary as citizens want to know why governments make particular decisions and what such decisions mean to them [28]. Though policymaking and analysis have been as old as human civilization, the modern era of policymaking goes back to the end of 1945, after the devastating World War Two, where many governments in the developed world began taking healing measures to their economies in order to tackle unemployment repercussions. Specifically, it was in the 1960s in the US that an enhanced public action was made to encompass antipoverty programs, combat racial discrimination policies, improve public health care, and other political measures [29]. Such measures were then emulated by other Western states to increase public expenditure and strove to ameliorate public problems such as urban deprivations which led growth rate to be accelerated.

However, despite that public policies are authoritative decisions on behalf of the public and the nation, Gerston [30], Edwards and Sharkansky [31], and Wu et al., [32] point out that there are always concerns and worries towards implementation gaps. For instance, Nwagboso [33], Ndah [34], Suberu and Egonmwan [35], found that the difference between government promises and their achievement are much common in developing countries and that of Africa in particular. Ethiopia is not exceptional to such implementation challenges. Findings by Afework and Fekadu [36], Habiba
[37], Omer [38], Atsbeha [39], and Taye [40], are only few case points.

\subsection{Defining Implementation}

According to Pressman and Wildavsky [41], implementation "means just what Webster [dictionary] and Roget [thesaurus] say it does: to carry out, accomplish, fulfill, produce, complete." To these two scholars, "...implementation is the ability to forge subsequent links in the causal chain so as to obtain the desired result." A more specific definition is provided by Van Meter and Van Horn [42] as: "Policy implementation encompasses those actions by public or private individuals (or groups) that are directed at the achievement of objectives set forth in prior policy decisions." These two scholars make a clear distinction between the interrelated concepts of implementation, performance, and impact and stress Dolbeare's [43] observation that impact studies typically ask "What happened?", whereas implementation studies ask "Why did it happen?"

Eugene Bardach [44] also introduced the concept of implementation 'games' as "classified according to the nature of their stakes", a "master metaphor" to understand what he calls, the "implementation problem." Bardach further defines implementation as "the playing out of a number of loosely interrelated games," and defends his metaphor by arguing that: "It directs us to look at the players, what they regard as the stakes, their strategies and tactics, their resources for playing as per the rules, 'fair' play". The game metaphor also directs our attention to who is not willing to play and for what reasons. Similarly, Rein and Rabinovitz [45] describe implementation as "the point at which intent gets translated into action." Their conceptual definition of implementation is "(1) a declaration of government preferences, (2) mediated by a number of actors who (3) create a circular process characterized by reciprocal power relations and negotiations." The scholars see the "politics of implementation" as being an attempt to resolve conflicts between three imperatives: "the legal imperative to do what is legally required; the rational-bureaucratic imperative to do what is rationally defensible; and the consensual imperative to do what can establish agreement among contending influential parties who have a stake in the outcome."

In one of the few attempts to model implementation in developing countries, Merilee Grindle [46] provides a generic definition as follows: "[lt] is an ongoing process of decision making by a variety of actors, the ultimate outcome of which is determined by the content of the program being pursued and by the interaction of the decision makers within a given politico-administrative context." The phrase "an ongoing process' shows us that policy is a process that never comes to an end even after termination other than being replaced by another. It also shows that both public needs and demands and government responses continue to operate despite a temporary lapse. To Mazmanian and Sabatier [47] policy implementation are "those events and activities that occur after the issuing of authoritative public policy 
directives, which include both the effort to administer and the substantive impacts on people and events."

The 'working definition' employed by Hargrove [48] includes two implementation components: "(a) the actions required by law are carried out; and (b) those actions encompass both formal compliance with the law and organizational routines consistent with compliance." Lastly, Stewart et al. [49] define implementation as a "process, a series of... decisions and actions directed toward putting an already- decided... mandate into effect." The scholars, in addition to viewing it as process, also take implementation in the form of output and outcomes where a number of actors, organizations, and techniques are made to involve (p. 10).

All the afore-listed definitions being equal, a widely accepted model of the causal processes of implementation still remains, what Hargrove earlier characterized as the "missing link" in social policy. Furthermore, the definitions what have seen so far inform us that policymaking does not end with the passage of a law by the parliament and its signing by the head of the state. That is only a shift from the top government house to the bureaucracy (departments, agencies, commissions of the executive branch) [50]. In addition to the existing organizations, there is also a need to create new organizations with new responsibilities that can translate laws (policies) into operational rules and regulations.

\subsection{Policy Implementation Researches and Underlying Theories}

To Schofield and Sausman [51], implementation studies are the outcome of intersection of public administration, organizational theory, public management research, and political science studies. Implementation researches emerged in the 1970s in the United States as reaction to the growing concerns over the effectiveness of wide-ranging reform programs. However, until the late 1960s and early 1970s, there were few studies in the area. To the views of Hill and Hupe [52], it was taken for granted that political decisions were all clear and administrators were thought to implement policies as per the intentions of the decisions made without encountering any difficulties.

\subsection{The Role of Leadership in Policy Implementation}

The concept "leadership" is not easily tenable to come to understand and reach consensus. According to Kouzes and Posner [53], there are over 225 definitions of leadership in the literature. This gives each scholar the liberty to define leadership in a way that works for his/her students, managers, government officials, community organizers, health care providers, and educational administrators. Consequently, Lemma Degefa [54] argues that whether leadership is of heroic or engaging has been a debate for many years where some scholars go to the extent of characterizing leadership definition as an "unfinished" project. But for some, leadership is what and how we try to influence the thinking behavior of other people or their professional lives.
Although Hill and Hupe as indicated earlier in their study that political decisions were clear and administrators were thought to implement policies as per the intentions of the decisions made, it was not found true in another study conducted by Barret [55], who proved that implementation processes were actually lagging behind their expectations. There are a number of instances where failure to "translating policy into action" has been common. It's from the backdrop of such intention deficits that studies on leadership's implementation role began to attract more and more attention. It also paved ways to analyze various phases of implementation researches that have direct bearing with the same.

According to Winter [56], most implementation researches trace back to the work of Jeffrey Pressman and Aaron Wildavsky's book Implementation. This initial research was a case study of an economic development program in Oakland California that had been created to stimulate minority employment. However, the program failed to achieve what it was intended due to complexity of actors who had to work together. The implicit problem to achieve the set goal was known to be a top-down implementation approach. In response to this implementation approach, Michael Lipsky's 'street-level bureaucracy' theory [57] forced political scientists to take a more serious consideration of what happens to policy after being passed by government. Consequently, a bottom-up implementation approach challenged top-downers, by making street-level bureaucrats' role, a compelling case for feasible policy implementation outcomes.

Though the "bottom-up" implementation perspective was a response to the dissatisfaction of many unsuccessful topdown policy outcomes, implementation researchers, had to find out the relative strength and weakness of both approaches with Elmore's third generation implementation research [58], known as the "combined" (synthesis) or 'hybrid' approach, that strikes balance between the strengths and weaknesses of the two. Hence, Elmore, together with Goggin et al., and others came up with what they considered combining "backward mapping" with a "forward mapping".

In this vein, policy implementation is considered as much a matter of negotiation rather than that of a command approach. In the absence of such interacting forces from both directions, May [59] characterizes it as "policies without publics", with little or no public inputs. To May, policies without publics are usually dominated by "technocratic expert opinions", whose implementation outcomes are considerably constrained, an obvious gap between the intended and the actual results or outcomes at the end.

Some scholars have gone a long way for defining leadership both from Biblical and professional points of view. Northouse [60] argues that leadership is a process to influences individuals and groups to achieve a common goal. Burns [61] holds that leadership is the ability to have a vision that is well communicated, build trust among colleagues, and take effective actions to realize set goals. Garey Yukul [62] on his part, characterizes leadership as that helps to influence others 
understand and agree about what needs to be done and how to do it. To Maxwell [63], too, leadership is the ability to influence others. One of the roles of leadership is also considered to challenging the on-going process, enhancing a shared vision, making others act, prepare the way and appealing to the heart. On the other hand, Laegaard [64] believes that leadership is composed of six wisdom keys: wisdom of balancing; seeing; forward-looking; engaging; depending; and anticipating. Laegaard further notes that leaders are also expected to have three major skills to achieve their goals: articulating plans (visions); articulating measurements; and communicating. Scholars including Heneman \& judge [65], Cottrell [66], and Guillory and Galindo [67] are also of the view that communicating skills is considered very important as it is an essential strategy for leaders to mobilize, aligning along set goals and inspiring them to move for action.

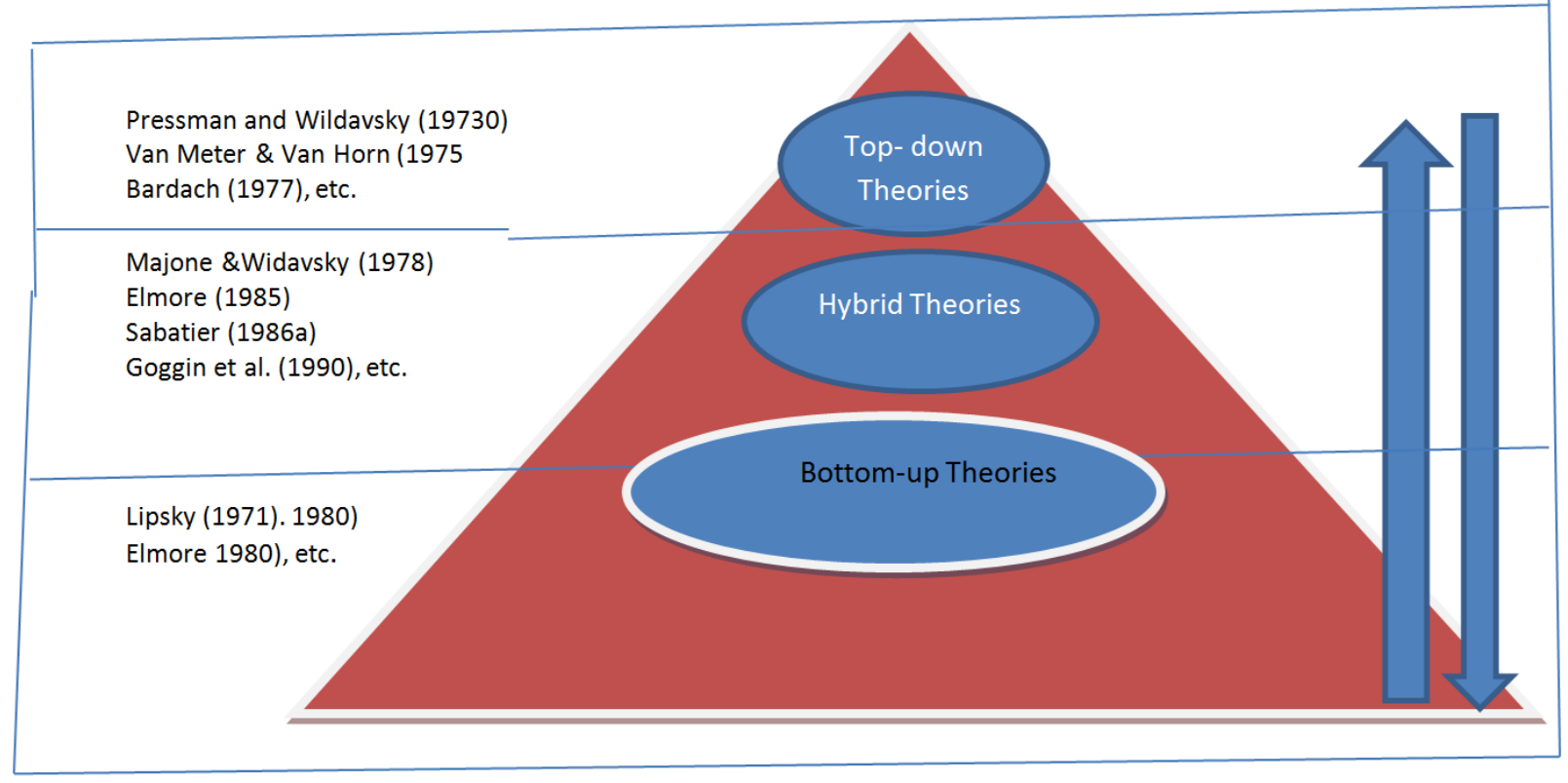

Figure 1. The three implementation Research Theories (Approaches).

There are also various theories with regard to leadership. Bass [68] lists down as trait, situational or contingency, team, and transformational approaches or models. Depending on their period and importance, each model has played significant roles in leadership in general and policy implementation in particular. For instance, the trait leadership model upholds the view that leaders are born with innate traits that distinguish them from non-leaders. Accordingly, there are considerations that some people are born with superior traits that made them leaders. Hence, Bass further goes that such individuals are different from "ordinary" individuals but having in-born intelligence, self-confidence, determination, integrity, and sociability. Furthermore, situational or contingency leadership approach prioritizes factors in the environment which impacts leader's behavior.

Finally, transformational leadership approach was initially coincided by scholars such as Downton [69] and later on by Bryman [70], as a "new Leadership paradigm". This style of leadership is considered now as most widely accepted, practiced, and researched approach. Transformational leadership treats employees as full human beings, people's emotions, values, and ethics into consideration. The model also believes that people can accomplish more than what is normally expected of them, provided they are given necessary support. In consequence, leaders and followers are bound together where collective good is given more regard.
To House [71] and Weber [72], charismatic leaderships are aspects of transformation leadership. Transformational leaders are likened to public figures such as Mratin Luther King, Jr. John F. Kennedy, Nelson Mandela and Mohandas Gandhi. On the other hand, it's important to note that that there is no leadership style that fits all situations, nor is there a 'full-range' leadership that shares attributes to transactional, transformational, or laissez-faire leadership. But the real fact is that at any point in time, leaders have irreplaceable role either for the success or failure of policy implementation.

\subsection{Empirical Research on Leadership and Policy Implementation}

Studies by Egonmwan [73] and Nnajiofor, Ifeakor and Mgbemena [74] show leadership roles are affected by a number of factors that hinder effective policy implementation. These include lack of political will, corruption and ineffective political leadership, overambitious and unrealizable policy goals, attitudes or behavior of the implementers (some people are impatient and overzealous), and lack of leadership continuity on a position. As proved by earlier study conducted by Zerihun and Tesfaye, the leadership lacks motivation, commitment, and communication of vision and inspiring their employees in Ethiopia. Moreover, they not only lack visionary leadership, but their accountability is not also delineated and spelt-out to 
the public and themselves. Consequently, findings from the aforementioned studies succinctly show that there is poor planning and an insufficient inter-departmental communication, on the part of the leadership, which both retards public sector reforms as well as diminishes the policy goals expected after implementation.

\section{Research Design and Approaches}

Research design is the way any research undertaking is framed based upon its objective. It's a means to elicit data on one hand, and the analysis we employ to reveal what the research has been intended to come up on the other. In other words, research designs are determined on the basis of our objective. Accordingly, this study was aimed at assessing the role of leadership in policy implementation and factors that influence them in discharging their entrusted leadership role. It attempted to find out why and what aspect of leadership will greatly influence policy success or failure. Pursuant to these principles, the research design opted was descriptiveexplanatory, while mixed research approaches (qualitative and quantitative) were used in order to get rich and relevant opinions of the participants. The use of mixed research approach also enabled the researcher to offset the weakness inherent in either of the two approaches and triangulate findings obtained from both data to arrive at sound conclusions.

Furthermore, the study employed both purposive and nonpurposive sampling techniques. Purposive sampling was based on the information from the mainstream media as regards the level of implementation of development policy programs and projects which are expressed in the form of service deliveries. The non-purposive sampling technique helped to obtain respondents in a probability sampling method (e.g. lottery method) to ensure some level of repetitiveness and also get data based on their number and relevance in the study public institutions.

On the other hand, the federal public institutions were purposively identified as reliable data sources for the study. They include Ministry of health, Document Authentication and Registration Authority, Immigration and Refugees Authority, Ministry of Labor and Social Affairs, and Ministry of Construction and Urban Development. Two federal middle-level leaders from each, ten together, were purposively identified. The selection of two middle-level leaders in each of the aforementioned public institutions was on two main accounts. First, as is the case in public service tradition in Ethiopia, members of the top public leadership are usually political appointees and inaccessible for practical research. Second, beyond providing political leadership as well as strategic directives, top leaders are not as close as to routine policy implementation activities compared to that of the middle-level leaders.

The next layer of respondents were those who make joint implementation decisions as well as who take direct implementation command from the middle-level leadership. They are characterized as senior experts or professionals.
Depending on the number of such individuals in each of the aforementioned five federal public institutions and relevance to the study, experts were identified with the help of heads of the directorate directors. Hence, instead of using probability sampling, senior experts were jointly identified to provide relevant information. In this vein, focus group discussants were selected from three public institutions rather than five to minimize uncalled-for repetitive responses. Accordingly, the number of discussants ranged from 7-12 senior experts. Upon taking the maximum number to be twelve, the total number of discussants was 36 (12X3). The last layer of respondents was the experts who, by virtue of their position and professional responsibility, are on the implementation frontline. The selection of such individuals depended on the relevance of the experts to the study under consideration. Consequently, through a lottery mode of selection, 15 experts on average from each of the five federal public institution was found important that could give 75 respondents altogether. This brought about the total number of respondents included in the study to 121 . Though this final number may seem smaller, from a deliberate more qualitative inclination than quantitative of the study, there was no assumption that the data obtained would significantly affect the outcome of the study.

The researcher employed questionnaire (close- and openended) and unstructured interviews that suit for probing as well as triangulating purposes. Moreover, relevant documents were analyzed to create links between past research outputs to the present as well as to substantiate current research findings. These instruments were used to collect views, opinions and facts from middle-level leaders, senior and junior experts. Relevant literary reviews were also used to triangulate and enrich the data obtained through the research instruments. As far as data analysis was concerned, survey questionnaires have been processed using SSPS version 20 and Excel 2010 Office application, while qualitative data obtained through key informant interview (KII) and focus group discussion (FGD) were described, analyzed and interpreted using thematic descriptive narrations. This helped to triangulate data obtained through both approaches as well as complement the limitations in each of the approaches. The unit of analysis were the experts who filled in the questionnaire, senior and middle-level interviewees and focus group discussants.

Finally, ethical clearance has been a primary requirement in order that the subjects or respondents who voluntarily gave their responses were not put at a disadvantage. To this end, the University issued a cooperation letter to the designated five federal public institutions, where empirical data had to be collected. Second and after meeting the heads of selected institutions, the researcher gave sufficient explanation as to the mission of the university and that of the current research in light of the study public institutions. Both KII and FGD informants and respondents were also given confirmation that providing their free and frank answers does not bring any side-effects against their wellbeing and interests as responses are not dispensed to any third party without their consent or 
knowledge, Consequently, they were made confident that their career life and interests are not affected in whatsoever.. Findings of the study were presented within the objective and scope of the study and as they appear except the substantiations so made to the interest of the reader.

\section{Data Presentation, Analysis and Discussions}

\subsection{Basic Information}

Rate of return of the dispatched questionnaire in selected federal public institutions has been all (100\%). This was attributed two main factors. First, the number of selected institutions was only five and the institutions are also located in the capital, and second data collectors who were gradate students, had been instructed and closely followed to leave no questionnaire paper behind. The following figure shows the demographic characteristics of quantitative respondents included in the study public institutions.

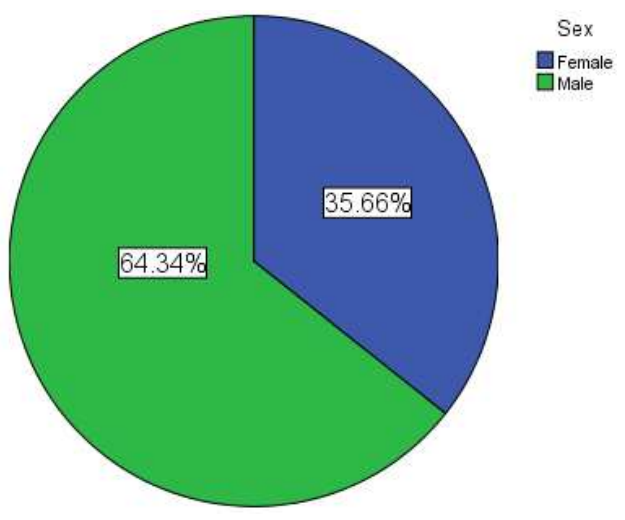

Figure 2. Sex of Respondents.

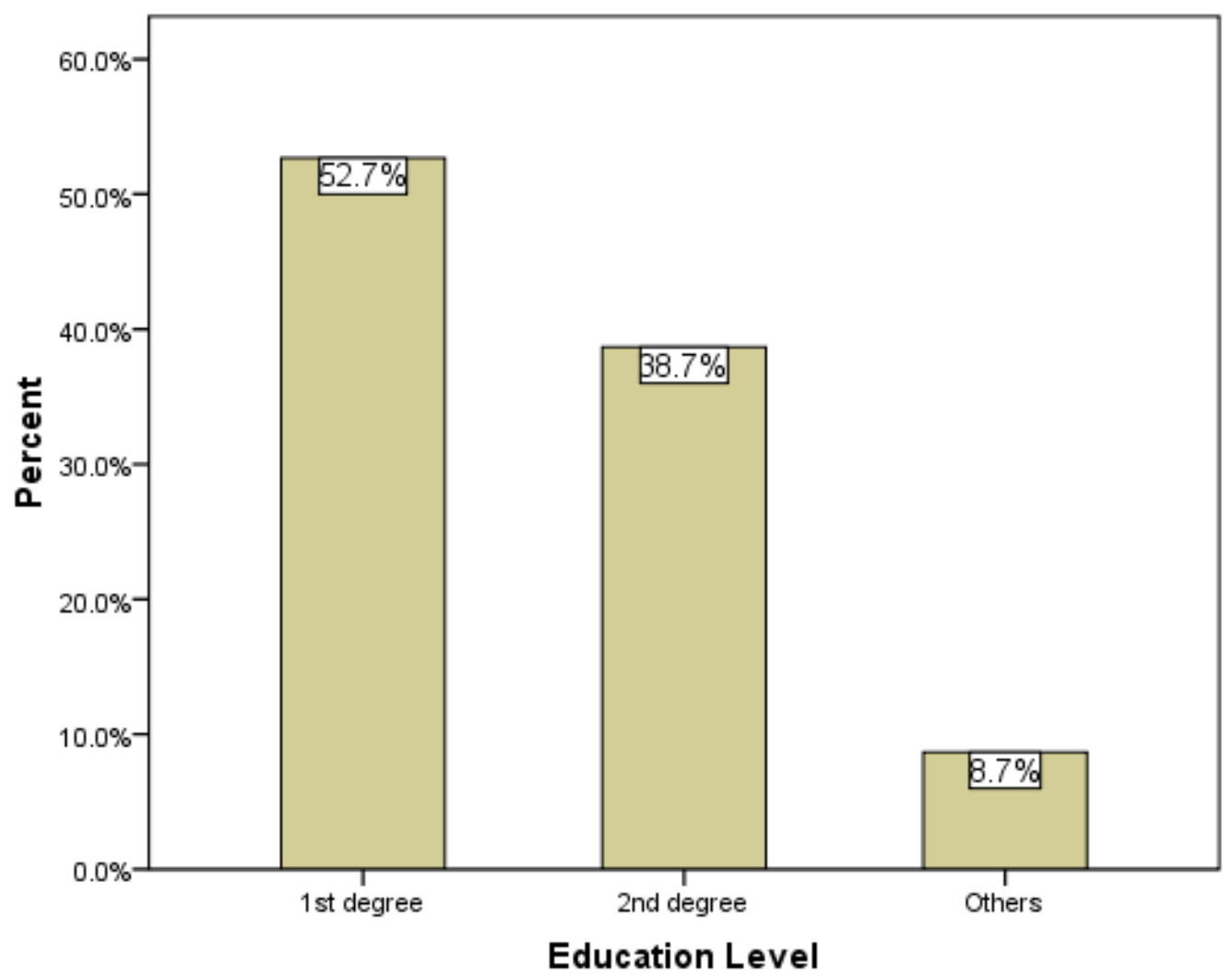

Figure 3. Education Level of Respondents.

As can be seen from figure 3, a great majority (64.34\%) of the respondents are male, while the rest $(35.66 \%)$ are female. This disproportionate representation is quite frequent even during the interviews and focus group discussions where females are represented with less than one third. As regards, the educational qualifications (Figure 4), most respondents are graduates of first degree $(52.7 \%)$, while $38.7 \%$ are with second degrees. Third degree though provided, did not attract anybody, while the "other" has attracted about $8.6 \%$ which could range from secondary, technical-vocational and training (TVET) program to the former diploma qualifications. Since a total of more than $90 \%$ of respondents are considered qualified, the responses provided by this group can also be taken as reliable views for the study. Interviewees and focus group discussants are senior experts and middle-level managers whose educational background can match with the responsibilities entrusted.

For a close correlation and reliability of the responses obtained, it was felt necessary that their professional experience was considered a proxy indicator. As a result, figure 5 below can help to draw possible conclusions on the relevance and validity of responses. 


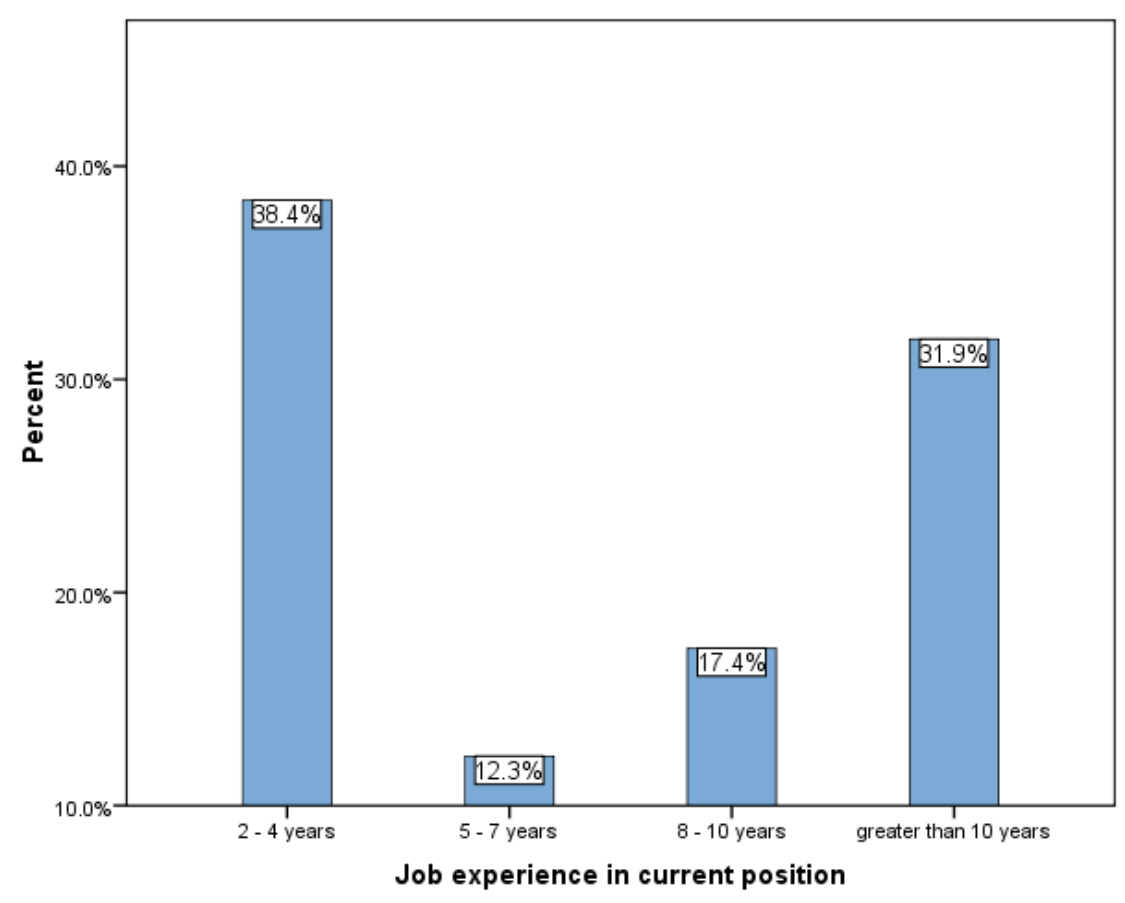

Figure 4. Job Experience in Current Position.

From figure 4 above, it can be vividly observed that respondents with 5 years and above constitute about $62 \%$ altogether, which implies that the study federal public institutions have good stock of staff who can understand the goals and objectives of their respective institutions as well as the role and performance level of a leadership in general and that of theirs in particular. Hence, it goes in tandem that responses provided by these individuals is based on their dayto-day critical observation of the relationship between sectoral policy implementation and the role played by the 1 leadership in respective public institutions under consideration.

\subsection{Data Presentation, Analysis and Discussions}

\subsubsection{Level of Leadership Role in Public Policy Implementation}

Conventional wisdom shows that leaders have an irreplaceable role in policy implementation much more than the employees. They have to design implementation strategies and coordinate the human and material inputs. The following figure explores the extent of leadership role in policy implementation activities.

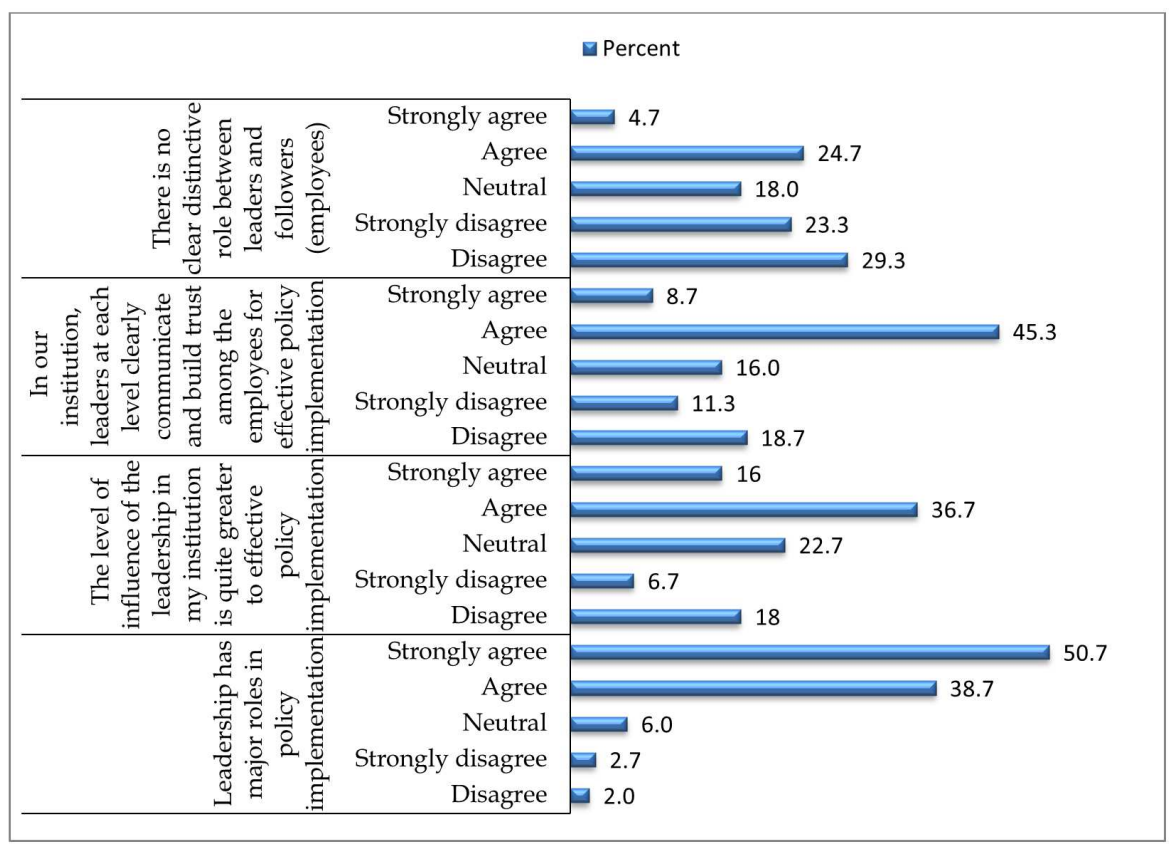

Figure 5. Level of Leadership role in Public policy implementation. 
Respondents have indicated their views for each of the four entries in figure 5 above. The first entry of the figure tries to find out whether or not there is distinctive implementation role between the leadership and employees. The result shows that majority $(52.6 \%)$ of the respondents strongly disagreed and disagreed respectively. The 'agree' group remained about $29 \%$, while $18 \%$ of them remained neutral respectively. The overall finding seems to favor that there is distinct role and span of control drawn for both groups. On the other hand, it is important to note that there are schools of thought that conform to the finding which the majority preferred, while others believe that both groups are there to accomplish common organizational goals.

Some schools of thought uphold that the role between the two has to be relaxed so that the flow of information can be of a "two-way" track in order to nurture cooperative and partnering spirit to to contribute to effective implementation. However, depending on the approach pursued, the common denominator remains the accomplishing of institutional missions where the leadership and the employees take individual as well as collective initiatives without an imposition and command-like administrative practices. Furthermore, in a bid to find out whether leaders at each level clearly communicate and build trust before embarking upon implementation, respondents have shown their agreement with almost $54 \%$, while the 'disagree' camp proved it with $30 \%$. Only $16 \%$ of the respondents were not in a position to determine the status. The fact that $54 \%$ of them are comfortable with what the leadership does in creating conducive and facilitative working environment is appreciated. Most policy implementation bottlenecks emanate from lack of common understanding between the leadership and implementers at the on set. This has been emphatically explained in the studies carried out by the former Federal Policy Studies and Research Center (PRSC) and also by Tiruye and Dereje. Weaver [75] and Scheberle [76] also have it that most institutional leaders downplay this role of reaching common understanding between and among potential players in the implementation process.

From figure 5, one of the essential roles that the leadership plays is policy implementation. As is obvious, implementation remains a measuring-stick either for reward or if not for stick (accountability). In response, a great majority $(89.4 \%)$ of the respondents strongly agreed and agreed respectively, whereas a negligible number of respondents identified themselves with 'neutral' $(6 \%)$, 'strongly disagreed' (2.7\%), and 'disagreed' (2\%) respectively. This finding testifies that leadership role is always decisive in policy implementation in particular. The grand agreement response, therefore, proves its (leadership) irreplaceable role. Key informant interviewees also indicated that "there can no any policy stage that the role of leadership can be imagined" (DA18 Feb/2019). It was further argued that public policy implementation, "without the ownership of the leadership is left to chances" or simply doomed to failure. The following summary responses from the interview and focus group discussion sessions also prove this reality:

Policy implementation needs leadership's close coordination and integrating all stakeholders. This is true of leadership as it has to interpret the promises that the government gave to the public via public policies. This task is a prime role of the leadership because the leadership is required to lead two things: the people and the policy to be implemented. Hence, neither public policy nor its implementation can be thought of without it, leadership (CTP 01 March, 2019).

Respondents, therefore, emphatically expressed their views that leaders in public institutions should not be routine task followers from the top, but need to be "sellers" of government political programs via public policies (CTP 01/March/2019); which implies their greater advocacy role to make implementation a reality. On the other hand, leaders are not only appraised with their knowledge.

\subsubsection{Leadership Influence, Approach, Effectiveness and Commitment}

It is believed that more than their knowledge and skills, the influence that the leadership poses on motivating and supporting their followers (employees). Table 1 below examines this state of affairs.

Table 1. Leadership influence, approach, effectiveness and commitment.

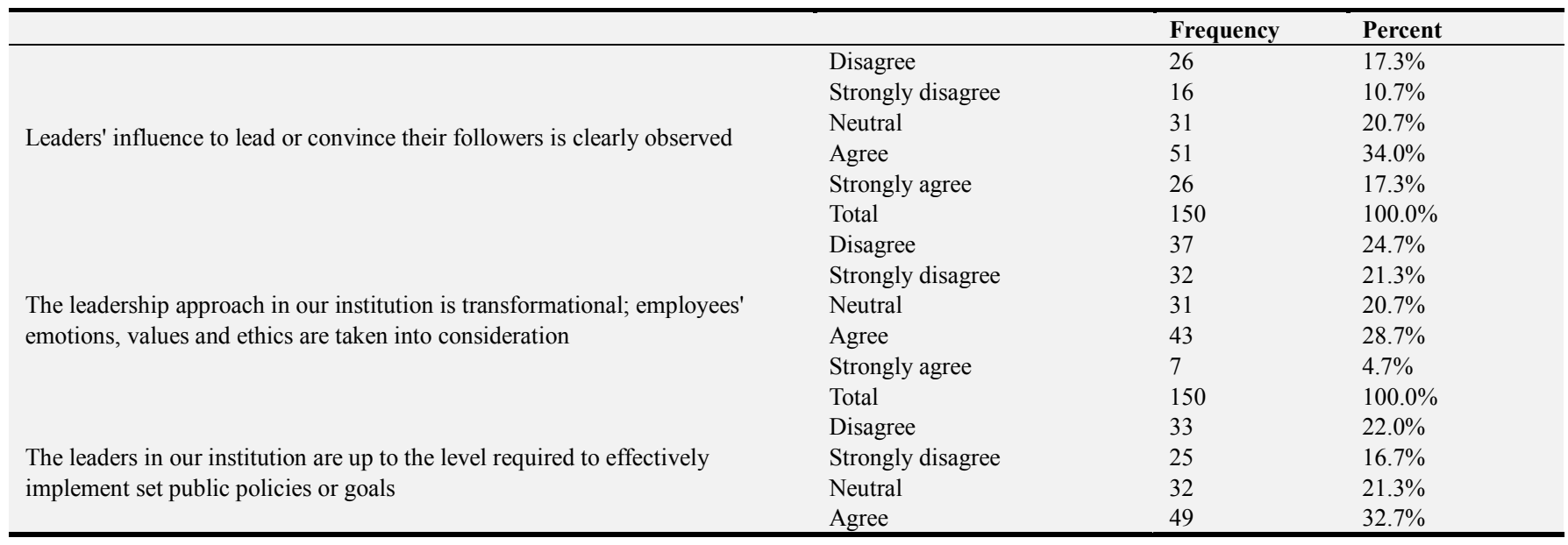




\begin{tabular}{llll}
\hline & & Frequency & Percent \\
\hline & Strongly agree & 11 & $7.3 \%$ \\
& Total & 150 & $100.0 \%$ \\
& Disagree & 33 & $22.0 \%$ \\
The level of leadership commitment in our institution is high & Strongly disagree & 25 & $16.7 \%$ \\
& Neutral & 28 & $18.7 \%$ \\
& Agree & 50 & $33.3 \%$ \\
\hline
\end{tabular}

Of all the main attributes of leadership, their influence, approach, effectiveness and commitment clearly reveal what are they for in the organization they are leading. As can be seen from Table 1, 28\% of respondents' disagreement, while $51.3 \%$ of them could fall together in the 'agree' category. The fact that around $21 \%$ of the respondents remained indifferent should be a concern. However, the 'agree' camp with only $51 \%$ cannot be considered reliable in the face of respondents who stood in the "disagree" and 'neutral' camps. Another important subject is the leadership approach being exercised in the study federal public institutions, whose response starkly indicated with $46 \%$ disapproval, while about $33 \%$ of them agreed that leaders in their institutions are transformational who take into consideration their employees' emotions, values and ethical norms. But the fact that a relatively significant number (about one-fifth) of respondents could not figure out the approach exercised by their leaders leaves one to contemplate on many things. First, such state of indifference may imply that some employees either do not know their leaders, or the span of leadership is considerably hierarchical. Second and in extreme case, is that this level of indifference may also be interpreted to a situation where some employees have no confidence that change will not come with existing leaders, tantamount to state of "hopelessness". An open-ended additional comment given by a respondent below also adds to the just aforementioned stance of the respondents:

Most leaders assigned in public institutions lack necessary knowledge and skills that match with the services to be rendered to the public. They (leaders) fail to lead ethically, responsibly and with determination. As such assignments are made by the top leadership, they (assignees) are not found effective and only there to "safeguard" (emphasis added) their position. This creates lack of trust and satisfaction against their performance in public institutions. Consequently, assignment of heads of institutions should not be based on their speech over the media or meetings, but with their proven institutional performance.

The next point is whether leaders in the study public institutions are up to the level required to effectively help implement set public policy goals. With the mediating neutrality clearly observed, $40 \%$ of the respondents strongly agreed and agreed respectively, while $38 \%$ of them disagreed. Leaving the indifference aside, response difference between those who agree and disagree is too narrow. It, therefore, seems that the role of public institutions' leadership is not clearly standing out boldly to the extent of deserving due appraisal or denouncement by their employees. Another speculation can be that the frequent turnover of the leadership since a year ago up to the present, might have had an impact on the respondents. That is, in a situation where they (respondents) are not able to precisely label the performance of their leaders, either as outstanding or poor, one can envision some problems that still need further investigation. The conclusion that can be drawn from the responses is that the status of policy implementation in the study federal public institution is not free from compromise or not in the right direction. Some senor experts and middle-level interviewees and focus group discussants have also alluded the causes for weak policy implemtation to the fact that competent experts are mistreated and leave public institutions: "Professionals are labeled as "rentseekers" and many of them do not want to stay while others do not wish to join public institutions. Leaders with political loyalties do not deliver a drop of service other than simply talking. If the ... sector policy implementation has to be successful, competent professionals have to be attracted to discharge their professional and national responsibilities".

As per the study conducted by the Federal policy studies and research center (PSRC), the above leadership assessment may not be fully accepted or denied in the face of recent corruption practices that has engulfed most of the public institutions in the country, in both urban and rural settings. Nor can we full-heartedly protect the complaints that the professionals lodge against the leadership. In consequence, it is not exactly clear to know the status of public policy implementation when measured in light of the role of leadership under question. Last entry under table 1 refers to the level of leadership commitment in policy implementation in the study federal public institutions. Scholars (e.g. Blanchard and Zigarmi, as cited earlier elsewhere, advance the view that commitment is a "prerequisite for policy implementation". Such commitments are supported by selfconfidence and motivation (p. 49). Respondents that fall into the 'disagree' camp constitute altogether about $38.7 \%$, while those that felt to agree to the prevalence of leadership commitment are $42.6 \%$. Again, with about $19 \%$ neutral respondents, there is no clear-cut distinction whether the study public institutions' leadership is either committed or otherwise. In a bid to project own implementation weakness, subnational institutions are made 'responsible' to clear out problems on this side.

The above argument may lead to two main conclusions. First, any implementation problems or deficits is due to "them" (perhaps regional states or other partners). Second, 
since there seems 'no problem at the federal level' (emphasis added), it opens an avenue for projecting accountability to others. By so doing, the common rhetoric "policyimplementation" dichotomy that is always heard of from top government officials and the mainstream media, is used as accountability shield in most of public institutions in Ethiopia. As mentioned earlier, Zerihun and Tesfaye have confirmed in their studies that among their four-five listings, lack of commitments of the leadership in reform policy implementation has been outstanding. The situation is interpreted as lack of accountability or "immunity" to implementation failures. This has been confirmed by Policy Studies Research Center (PSRC). Furthermore, at one point, one of the Federal Speaker of the House in one of the regional states had to say the following:" The problem of commitment is manifested at all levels. But that of the leadership stands tall" (Interview 2017). Similar studies in Nigeria by Ikechukwu and Chukwuemeka [77] have also proved this same challenge, where some corrupt leaders and those seeking personal self-interest are almost immune to accountability. In fact, Tiruye and Dereje also found out that lack of leadership commitment in public institutions emanates from "implementation accountability that crosscuts all walks of life, and where there is no distinction between the rank-and-file..." (p. 77).

\subsubsection{Leadership Competence and Commitment, Strategic Role, Cooperation and Implementation Performance}

Leaders are expected to have and exercise competence, commitment, play strategic role, and forge cooperation in policy implementation drive. These are essential attributes as well as responsibilities of any public institution leader. The next Figure 7 examines whether the attributes hold true in the study federal public institutions.

As seen from figure 6 above, respondents for the first entry (competence and commitment) indicated their agreement with $35.3 \%$. Those who disagreed constitute $41.3 \%$, while $23.3 \%$ of them remained neutral. Since, the response on both sides of the scale does not clearly indicate leaders competence and commitment, and with nearly a third of the respondents remaining indifferent, the overall observation suggests that leaders' competence and commitment attributes could not be clearly stand out. But the fact that close to $50 \%$ respondents disagreed to confirm the given attributes still remains a concern, if not grave.

The second entry in figure 6 demands respondents to indicate their belief or view if recent policy implementation in their institution did really implicate the strategic role of their leadership. In response, $44.7 \%$ of the respondents positively confirmed, while $33.3 \%$ of them denied it and $22 \%$ opted to remain neutral respectively. Though not sufficient, the 'agree' group are by far sensible despite that almost half of that number of respondents could not either prove or disprove the subject. As to forging the spirit of institutional cooperation, $46 \%$ of the respondents indicated their agreement, while $35.3 \%$ of them disagreed. Leaving the indifferent group aside, those who agreed that leaders in their institution forge institutional cooperation are relatively in higher ground. In other words, leaders in the study five federal public institutions are attempting to realize cooperation among the employees, or some wind of changes is being blown. But the overall impression tacitly implicates that there is leadership deficit which is a 'wake-up-call' for the government to do something about it.

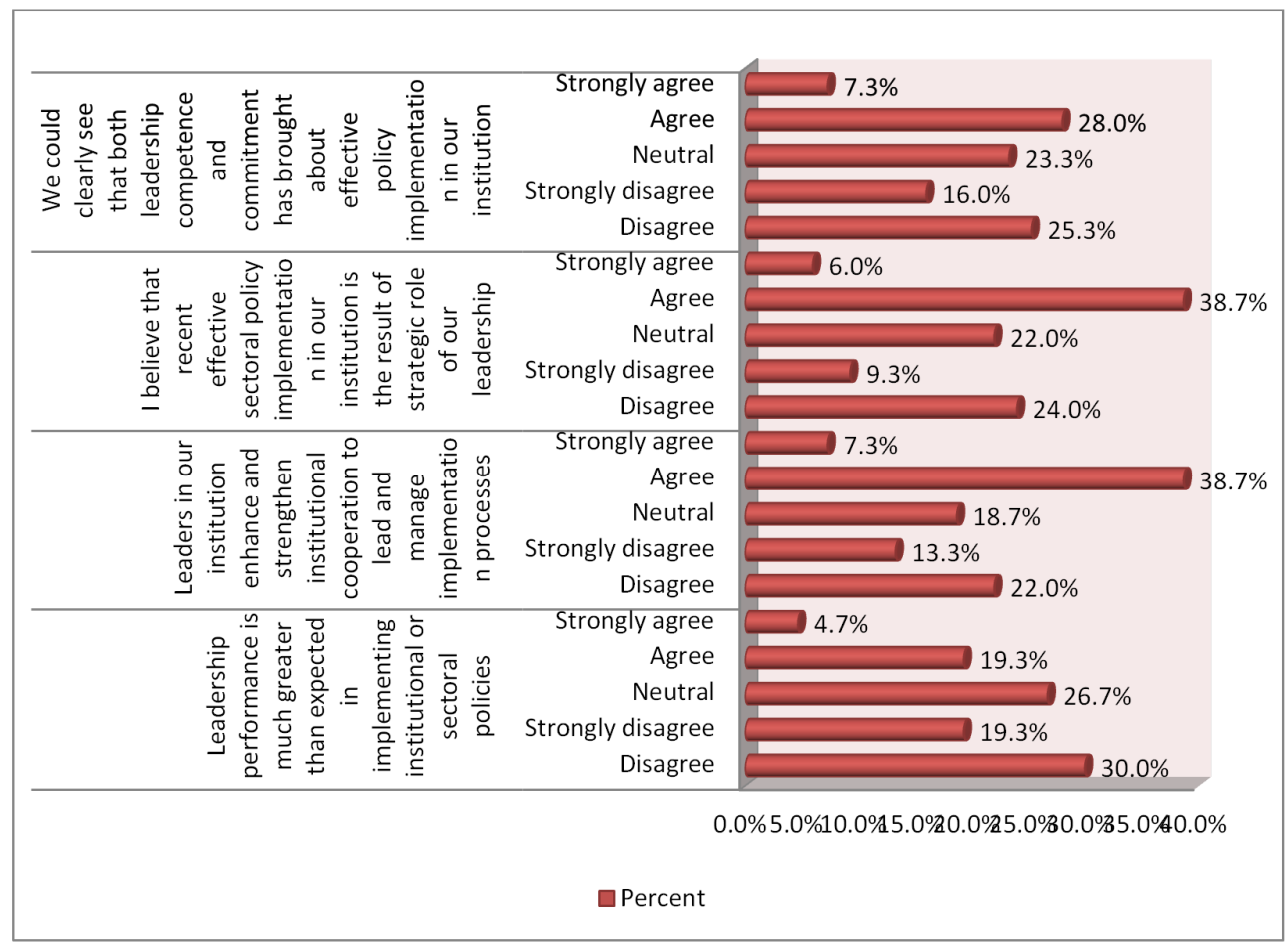

Figure 6. Leadership competence, commitment, strategic role, cooperation, and implementation performance. 
The last entry of the figure, leadership performance, is greater than the expectation of respondents in the study federal public institutions. Responses confirm that about $49.3 \%$ declined the expectation of their performance, while only $24 \%$ of them agreed. Respondents with neutral response almost constitute $27 \%$. While the 'agree' and 'neutral' groups are of great majority together, those who denied leadership performance to excel are still of substantial number. This response, with previous doubts, may lead to a conclusive view that there is some leadership problems brewing up but remain unnoticed by relevant government branch. In addition, both interview and open-end responses seem to confirm the prevalence of greater concerns as follows:

Current leadership do not pay due attention whether or not they performed a task entrusted to them. It makes no difference to him or her as their salary and benefits are always maintained. Even after demoted for poor implementation performance, they will be promoted elsewhere again. There is no question of accountability for their poor performance... That is why main robbery practices are found rampant throughout the nation. This requires restructuring of some of the sectors.

In fact, this same practice has been found by a study conducted nationwide by the PSRSC. It is given here in

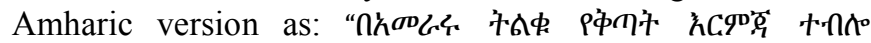
poq 久

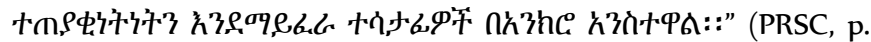
92). This undoubtedly shows that leaders in the study public institutions have also little concern when it comes to real accountability upon failing to perform entrusted public responsibilities, policy implementation challenge being the main one.

\subsubsection{Leadership Style Frequently Witnessed or Exercised in the Study Federal Public Institutions}

Leaders have various styles to influence their followers (employees) while mobilizing the latter for accomplishing set policy tasks. Table 2 next deals with the subject under question.

Table 2. Leadership style frequently witnessed or exercised in the study federal public Institutions.

\begin{tabular}{|c|c|c|c|}
\hline & & frequency & Percentage \\
\hline \multirow{6}{*}{ 1. Most of our institutional leaders practice } & a. Trait theory taken from their predecessors of family member practices & 53 & $36.1 \%$ \\
\hline & b. Contingency or situational theory that can fit emerging challenges & 47 & $32.0 \%$ \\
\hline & c. Transformational theory to achieve goals by stimulating and inspiring followers & 18 & $12.2 \%$ \\
\hline & d. All of the above & 14 & $9.5 \%$ \\
\hline & e. None of the above & 15 & $10.2 \%$ \\
\hline & Total & 147 & $100 \%$ \\
\hline \multirow{5}{*}{$\begin{array}{l}\text { 2. If your answer for question } 1 \text { is 'a' (trait } \\
\text { theory), this type of leadership will contribute } \\
\text { to: }\end{array}$} & a. Effective policy implementation and goal achievement & 7 & $7.7 \%$ \\
\hline & $\begin{array}{l}\text { c. Cannot inspire colleagues and followers and this will lead to } \\
\text { implementation deficits }\end{array}$ & 11 & $12.1 \%$ \\
\hline & d. 'b' and 'c' can be the possible responses & 59 & $64.8 \%$ \\
\hline & e. None & 8 & $8.8 \%$ \\
\hline & Total & 91 & $100 \%$ \\
\hline \multirow{4}{*}{$\begin{array}{l}\text { 3. Most leadership practice or model in your } \\
\text { institution is: }\end{array}$} & a. Top-down & 97 & $69.3 \%$ \\
\hline & b. bottom-up & 6 & $4.3 \%$ \\
\hline & d. none & 7 & $5.0 \%$ \\
\hline & Total & 140 & $100 \%$ \\
\hline \multirow{4}{*}{$\begin{array}{l}\text { 4. In your sectoral or institutional policy } \\
\text { implementation, which one of the following } \\
\text { leadership style do you think dominates most }\end{array}$} & a. More technocratic or expert-led & 73 & $57.5 \%$ \\
\hline & b. Considers public or stakeholders' opinions & 54 & $42.5 \%$ \\
\hline & Total & 127 & $100 \%$ \\
\hline & a. Lack of delegation & 11 & $7.8 \%$ \\
\hline \multirow{6}{*}{$\begin{array}{l}\text { 5. Which one of the following leadership } \\
\text { attributes or behavior do you think negatively } \\
\text { affects policy implementation? }\end{array}$} & b. Corruption & 5 & $3.5 \%$ \\
\hline & c. Overambitious & 28 & $19.9 \%$ \\
\hline & d. Lack of continuity of leadership & 40 & $28.4 \%$ \\
\hline & e. All can affect & 34 & $24.1 \%$ \\
\hline & f. None & 23 & $16.3 \%$ \\
\hline & Total & 141 & $100 \%$ \\
\hline
\end{tabular}

Table 2 attempts to find out the common leadership style used in the study federal public institutions. While almost all of the five entries were deliberately planned to exhaust the leadership practice in place using different questions, it was for the same objective: the leadership style or practice that is behind policy implementation in the study federal public institutions. Accordingly, most respondents seem to agree that trait leadership theory dominates the actual practice and confirmed this with $36 \%$, while $32 \%$ of them proved to rally around contingency or situational leadership style. In quite contrast, only $12.2 \%$ of the respondents attributed to transformational type, while the rest $9.5 \%$ and $10.2 \%$ of the respondents either favored all types of leadership practice or found it difficult to figure out the actual leadership model operating in their institutions respectively. With no doubt, the finding shows that the operating leadership style is inclined to what is considered path dependence and does not aspire to invent a new wheel other than maintaining the status quo in 
place. In support of the finding, the following comments have been forwarded from group discussants as:

Our leaders are accustomed to the trait type of leadership with no innovative way of doing things. They do not pusue a problem-solving approach and generate new ideas. Most leaders await guideline or order that flows from the top with no self-confidence. Instead of being visionary and innovative, most leaders appear 'burden' for the government. And they are only there to "safeguard" their positions... (FGD, SMA 19/2/2019).

The second entry responses in Table 2 clearly indicate that trait or situational leadership dominate the study federal public institutions resulting in weak policy implementation and goal achievement. In consequence leaders are not in a position to inspire their colleagues and conclusion was reached with a great majority of $64.8 \%$ of respondents. Related to entries one and two of the same table, response to top-down approach attracted as much as $69.3 \%$, while its opposite (bottom-up) was supported only by $4.3 \%$ (Question number three). Such top-down approach is the dominant working procedure of many leaders in almost all government institutions in the country. As mentioned elsewhere in this study, scholars such as Lipsky and Goggin et al. further argue that top-down implementation approach favors the concentration of power at the top while closing the way for negotiation between the top bureaucracy and front-line implementing stakeholders. However, it is important to note that both domestic and international research practices by the aforementioned scholars have proved considerable implementation deficits abroad and in Ethiopia too. In the absence of participatory policy environment, policies are driven without 'passengers' (stakeholders), which Peter J. May rightly characterized it as "policy without publics" (p. 194).

Policy without publics simply means that all the relevant publics, stakeholders such as professional associations, producers and consumer groups, trade organizations, interest groups, etc. that surround common issue interests do not take part in either of the above policy activities, including its implementation. Focus group discussants and interviewees consulted also had their reservations that a "technocratic leadership may not fully respond to public's demands to the level desired". While it's true that policy decision is the derivation of political decision, this does not necessarily imply that each and every implementation aspect is to be decided politically; there is time when and where practical professional action is also necessary. Consequently, the extreme role ascription either exclusively to experts or to stakeholders needs to concede to the positive interplay of both entities. Interviewees and focus group discussants also supported the role of both technocrats (experts) and at the same time the "advantage" of the role the stakeholders and general public at the implementation end. This further confirms that there is no one single institution that can help realize implementation in its fullest sense.

Finally, respondents were inquired to identify leadership behaviors negatively affect implementation in their respective institutions. Accordingly, responses have spread along factors such as lack of delegation $(7.8 \%)$, corruption (3.5\%), overambitious policy goals $(19.9 \%)$, lack of continuity of leadership $(28.4 \%)$ respectively. Of all the responses, lack of leadership continuity (28.4\%) seems to stand tall. This particular issue has drawn the attention of almost all interviewees and focus group discussants. In particular, two of the federal public institutions (CTP and SMA) consulted interviewees and focus group discussants expressed their grim feelings about the rate of leadership turnover. They believe that such instable institutional practices lead to loss of institutional memories and paves way to escaping accountability since it's difficult to easily trace or ascribe implementation failure either to the previous or current leadership.

In consequence, discussants are of the opinion that " as new leadership frequently comes in, previous plans are kicked out either officially or implicitly, in a bid to 'overstate' their own 'new' plan to get temporal acceptability by top leadership", but negatively affecting the effective implementation of many public institutions in the country. They also add that as an antidote, it's important to have leadership criteria at national level to minimize or do away with the spontaneity of assigning leaders regardless of their professional and ethical merits.

\subsubsection{Ethical Norms, Forward-looking and Delegation of Tasks}

As per entry one from Figure 7, respondents were requested to rate the level of leaders' ethical norm. The "high" and 'medium" respectively account for $87.4 \%$ of the entire respondents, while $12.7 \%$ of them categorized it as "low". But it's important to note here that this finding is quite opposite of the other leadership attributes revealed so far, imply at times respondents tend to remain inattentive to keep their responses that preceded. On the other hand, whether the study institutions' leadership is inspiring in mobilizing employees toward set institutional goals (set policy objectives), about $15 \%$ and $47 \%$ have agreed to 'high' and 'medium' respectively, whereas about $38 \%$ of them ascribed them to "low" level. Though majority of the respondents confirmed above medium, the $38 \%$ who had critical doubt and did confer them 'low' is still a concern as well as needs further investigations.. As to the future-looking traits of the leadership in the study federal public institutions, it can be said that a great majority of leaders (65\%) have been confirmed as 'high' and 'medium' respectively. Still, $35.2 \%$ of leaders that are labeled as "low" which remains a grave concern.

Finally, it is believed delegating roles to individuals and groups help them feel sense of ownership and partnership. In a bid to know the status of delegation about $83 \%$ of respondents confirmed 'high' and 'medium' respectively, while about $17 \%$ of them allocated a 'low' level position for their leaders. As clearly mentioned else where in this study, driving policy implementation without sound delegating of tasks and appropriate participation of individuals and groups. will eventually result in "policy without publics", weak-links that also negatively affects implementation effectiveness. 


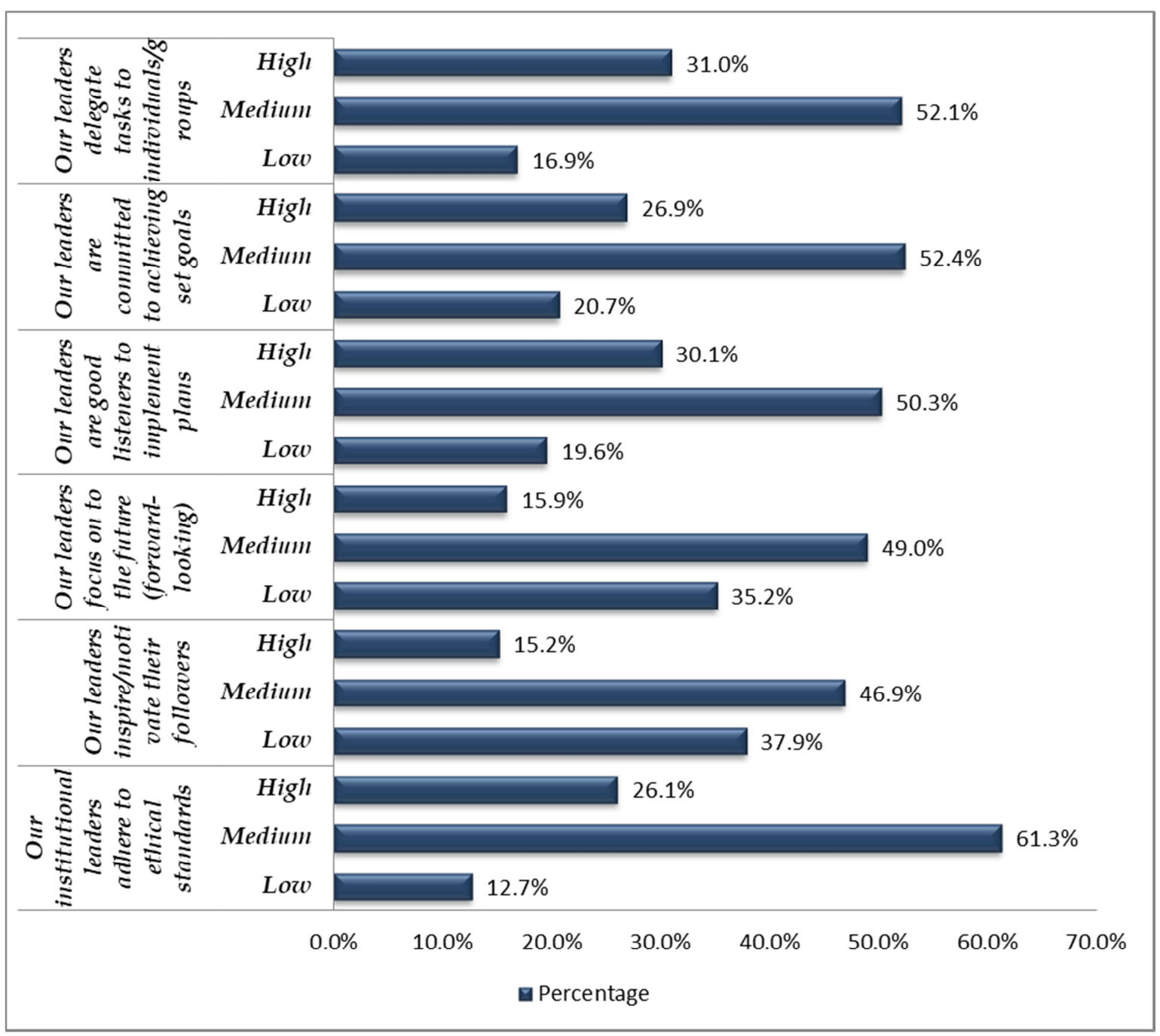

Figure 7. Ethical norms, inspiring role, forward-lookng, listening and delegating tasks.

The last figure (Figure 8) deals with whether or not leaders abuse their authority, exercise dictatorial practices, looking after conflicts to bringing solution without which they may create implementation gaps between leaders' capacity and institutional desires. Hence, the likely abuse of power and its extent is confirmed by $56 \%$ of the respondents to be high; $27.3 \%$ as medium, while $16.5 \%$ conclude it as 'low'. Even if the medium abuse of power (authority entrusted) is coupled with the responses of the majority (56\%), it can easily be discerned that the situation is not only worse but the staus of implementation as a result is also substantially detrimental. Moreover, respondents were inquired to determine the tendencies of their leadership practices to generally categorize their leaders either as democratic or dictatorial in their day-to-day encounters. Responses provided together vividly show that over $80 \%$ of them rated as "high" and "medium" respectively. It's only about $18 \%$ of the respondents that proved "low" to explain the situation. In short, most of the leadership in the study federal public institutions exercise non-friendly leadership style which would largely mean to favor dictatorial tendencies. In an attempt to find out how far leaders are apt enough to find out causes for conflict and resolution, about $81 \%$ of the respondents treated as high and medium respectively, while around $19 \%$ witness edit as low. This again shows that there is a serious challenge to have pro-active leadership in the study public institution. It also implies that in the absence of proactive leadership conflicts are often times encountered and attempt to resolve them are also considered minimum. The other side of the coin is that the rate of policy implementation is considerably affected by such reactive measures after which things go out of hands.

\subsubsection{Leaders'Abuse of Power, Conflict Resolution, Institutional Desires and Their Policy Implementation Capacity}

In the exercise of their power, leaders may use or abuse it during policy implementation. However, the expectation is that they adhere to using of power only for the effectiveness of the policy to be implemented as well as to the rights of the employees. Figure 8 next shows the extent of use of power, efforts exerted to resolve institutional conlicts, fulfilling institutional desires using their implementation capacity. 


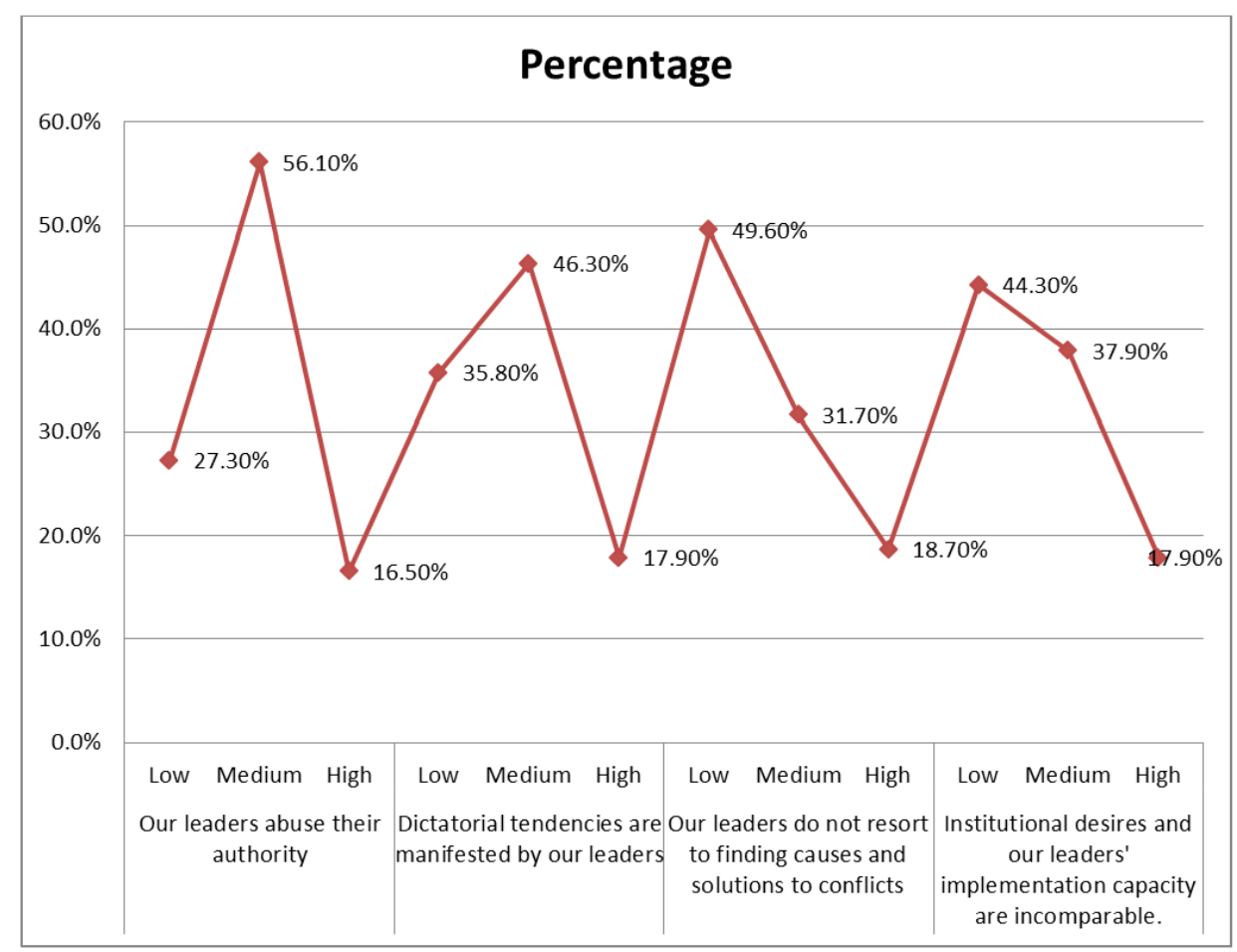

Figure 8. Leaders' abuse of power, tendencies manifested, causes of conflict and resolution, and institutional desires and policy implementation capacity of the leadership.

As can be seen, the final entry in Figure 8 above looks at whether public institutions' desires and leaders' implementation capacity can match or incomparable. To this end, the responses clearly indicate that $44.30 \%$ and about $38 \%$ of the respondents proved high and medium respectively. In other words, the mismatch between institutional desires and what implementation capacity leaders have do not match or even if there is, it's considered 'medium'. Added to that, about $8 \%$ of the respondents are confident to categorize the implementation capacity of these leaders to be low. The overall finding of this specific issue in the study public institutions is a concern. Moreover, it can also be argued that most public dissatisfactions are fed by incompetence of the leadership in policy implementation and this finding can be extrapolated to other similar public institutions. In light of their strategic positions (their closeness to the top-level or political appointees and their interpretive role of strategic reforms or changes), these middle-level leaders are expected to be the prime actor in the implementation process. Lack of this implies many things: their assignment was not in direct congruence with their knowledge and experience, or for unknown reason, they are not motivated to lead and accomplish tasks entrusted to them.

The final points discussed with qualitative respondents focused on the challenges that leaders in public institutions might face in discharging their responsibilities. They emphasized the lack of partners commitments, when on one has jurisdictions over the other while failing to discharge own share; when there is no motivated staff to accomplish both individual and group assignments, absence of minimum required resources to run the planned policy or program and the frequent turnover of the leadership, could significantly affect their leadership performance and inspiration. As a response, the same respondents summarized measures to be taken as follows: transparent and meritocratic-based leadership assignment; measurement of the leadership on the basis of outcome-based performance principle; frequent cross-peer evaluation system to be in place; frequent in-built follow-up and evaluation performance; limited term of office for the leadership position; and designing and applying leadership criteria to both assign and holding them accountable for tasks or assignments not done as per the standard.

\section{Summary of Findings, Conclusion, and Recommendations}

\subsection{Main Summary Points}

This study attempted to find out the relationship between policy implementation and the role of leadership in five federal public institutions in Ethiopia. The design selected for the study was descriptive-explanatory in order to describe, explain and interpret the findings. The approach used was mixed where both quantitative and qualitative were collected from the filed. Data sources have been purposively selected where five federal public institutions have been used on their relative track record of policy implementation in recent years. Research instruments such as questionnaire, interview and focus group discussions have been used to collect the 
empirical data. Secondary data have been employed to provide research background, justifying current study and also substantiating the findings. After having organized, described and triangulated data, the following main findings could be recorded:

1) While leadership is believed to be evaluated on the actual performance merit it undertakes based on set institutional vision and missions through its influence of planning, coordinating, support and follow-up, such clear list of tasks and activities are not specifically spelt-out and given to the study federal public institutions leaders. Its absence has severely affected implementation of institution-based and national policy implementation outcomes. Respondents affirmed that the problem has been gravitated by frequent turn-over of the leadership where institutional memories and sequence of planning activities are messed up. In short, there are no specifically charted out role to adhere such that upon failing to discharge entrusted policy responsibilities will amount to facing accountability or reprimands in any form.

2) The study has also come up with the view that the role of the leadership in policy implementation is incontestable and is of strategic importance. This has been supported and agreed by $89.4 \%$ of the respondents. The two qualitative data collecting instruments further expanded this role to indispensability of a higher level without which the whole issue of policy and its implementation remains mere 'rhetoric', and devoid of planning, coordination, follow-up and support and finally evaluation. Such level of coordination and implementers' coalition-building can only save the common implementation deficit practices frequented in most of public institutions in the country.

3) In the study of selected federal public institutions, leaders' commitments has been found both questionable and debatable. For some of the respondents, the issue of commitments is not under question in their institution and some respondents tend to be 'protective' both on their own behalf and their top leadership counterparts, while other respondents clearly explain the much obvious lack of commitment of their leaders. The latter support their substantiation with the practice in their own ministry/agency/ that leadership commitment is either too weak or non-existent by citing their institutional policy and plans that have slacked operation but no one is questioned as to why things do not move as intended or get implemented. Lack of commitment is mainly attributed to lack of accountability and 'political immunity', serving as protective 'shield'.

4) Absence of accountability upon policy implementation failure is a fait-accompli issue in the leadership circle at least in the study federal public institutions because of some alleged proxy factors. First, some respondents attribute policy implementation accountability failure to the current arrangement of federal governance, where they project it to "they/them" which unfairly places accountability on the regional states. In fact, this escapegoatism has created diffusion of responsibility and accountability on both sides of the scale. As a result, most respondents look at the whole accountability fabric to be in jeopardy at all levels of governance. Causes are quite vivid to the respondents on the following accounts: not clearly spelt-out accountability criteria; political immunity and logrolling in the leadership circles; problem of leadership continuity; and the replacement of accountability by 'reward'. Second, arguments also goes to lack of leadership continuity, as observed by Egonmwan in Nigeria, that paves ways for a situation in which previous policies are "abandoned" and tripping personal ego flourishes to install new ones that "pays off" personal glories rather than looking for achieving institutional missions.

5) Nowadays, leadership scope has become inestimable. The role of government is ever-expanding despite continuous efforts being exerted to downsize government structures as well as outsourcing of some services. According to Pollitt [78], the outcome of being outnumbered by ever-emerging public demands has made the quest for policy efficiency and effectiveness intractable. It also goes that all of these burdens directly reflect on the role and responsibility of the leaders. Hence, what came out as hampering leadership commitments in the study federal public institutions has also been revealed as follows: lack of spelt-out leadership criteria; lack of empowerment (most decisions are made at the very top level and with scarce reoources to implement); varied partnership level; unmotivated staff; over-expectations from the beneficiaries; and frequent leadership turn-over have been pinpointed as obstacles that have negative impacts on policy implementation in the study federal public institutions.

\subsection{Conclusion}

Quite a number of policy scholars believe that the successful implementation of public policies depend on externally and internally located driving forces, while leadership is considered as the external driving force but yet remains most decisive. On the other hand, the commitment and competence of individual staff members is regarded as internal forces that also facilitate successful policy implementation. This study has raised various issues pertaining the role of leadership in policy implementation in the selected federal public institutions in Ethiopia. Having its obvious limitations, the following salient conclusive points have been drawn:

i. Other than the traditional assumption that any leader in any public institution can lead, there are no specific coded leadership roles and responsibilities that can serve as measuring stick of accountability in the study federal public institutions. This problem may be shared, 
to some extent, by other public institutions in the country.

ii. Leadership commitment in the study federal public institutions was not rated to the level expected: clear manifestation could be relied on as it relates to many of the sectoral policy implementation outcomes. Effective policy implementation is only possible with self-less personal evaluation to answer what goal has been achieved or otherwise. In the face of impersonal policy evaluation, the question of commitments and accountabilities are made to distance afar.

iii. The underlying cause for little or total lack of accountability upon failing to deliver intended service or implement a policy, could have a long listing wish. But lack of clear crieteria and above all, 'political immunity' seems to stand tall.

iv.Besides several limiting factors, leaders' capacity, partners with varied interests, under-motivated staff, limited basic resource allocation, lack of empowerment over resources, frequent turnover of leadership and related others appear as counter-efficient, effective and transformational state of affairs still continue operating in the study federal public institutions in Ethiopia.

\subsection{Recommendations}

This study has attempted to shed some lights as regards the role of leadership in policy implementation in selected federal public institutions. In light of the few selected federal public institutions for the study, recommendations may tend to be out of scope as generalization based on limited data base may not sound wiser. If it were not for time and also financial constraints, the researcher fully understands that the delimitation of the study to few federal public institutions could not provide full answers for the research questions. Having not included sample leadership role in the regional states is also a clear limitation to attempting extended recommendation. Nevertheless, and taking current findings as a baseline, the following points are forwarded by way of suggestions to be considered by the study federal public institutions and other government bodies in charge.

a) It is important today, more than ever before, to re-think of the role of leadership in policy implementation. People in this position have prime task of leading diverse policy partners to implement public policies. Both government and the public look for public policy goals to be achieved and the latter benefit from the same. Unlike in the past, where leaders in public institutions are only concerned with few and routine activities, now it turns out to be engaged and engaging employees in strategic institutional, local and national policies and related issues. Leaders have to be convinced that their new and prior role is to advocate and champion policy leadership and its effective implementation.

b) In a world of diverse and overlapping leadership role unabated, there is a dire need for continuous capacity building that can nurture confidence and transformational skills in leaders so that they can inspire and influence their colleagues and the entire institutional staff to be mobilized for effective policy implementation drive.

c) Ensuring leadership empowerment has been discussed in both covert and overt ways during the focus group discussion and with the key informants. The underlying concerns sheds some lights that policies are decided elsewhere and institutional leaders are 'instructed' to implement without prior knowledge and understanding. It is, therefore, important to make public institution leaders to be at the center-stage of public policymaking endeavors so that they have the knowledge as well as confidence to elicit their determination for policy implementation. This adds to their implementation stamina and helps rally their partners for a common implementation goal.

d) One of the major concerns reflected in this study is leadership continuity and their terms of office. Most respondents ascribed lack of continuity to the likely 'abandoning' of previous policies as well as diffusion of accountabilities as a result. At a glance, both concerns are competing factors. However, striking the balance is quite necessary by maintaining institutional memories on one hand, and making the term of office both competitive and meritocratic, on the other.

e) Lack of leadership accountability and absence of speltout leadership code have been discussed at length having direct implication to each other. Though limits to today's leadership role seems somewhat bound-less, some operational and pragmatic code of conduct to all public institution leaders need to be put in place. Doing so, may perhaps, reduce some of the frequently reported leadership misbehaviors such as corruption and dictatorial tendencies in public institutions.

f) In light of the ever-widening role of the leadership as well as the stringent level of accountability to be adhered, there is a need for designing incentive packages for this group of 'public servants' in order to boost their commitments and leadership morale in a bid to discharge their entrusted public responsibilities.

g) Finally, this study only dealt with the tip of the iceberg, with regard to the role of leadership in policy implementation. To this end, an in-depth and encompassing research proposal and the conduct of a comprehensive study is recommended to come up with more reliable findings.

\section{Acknowledgements}

The researcher would like to thank all individuals and groups who participated in this study. In particular, my sincere thanks go to the study federal public institutions and the focal persons who coordinated the collection of data to have been made possible. I would also like to thank the Ethiopian Civil Service University in providing the research fund without which this study could not have been realized. 


\section{References}

[1] Adamus-Matuszynaka A. 2001. Implementing new public policy in Poland: barriers and stimuli. Journal of European Studies, 9 (2).

[2] Alebachew Asfaw Y. 2019. Exploring the Strategic Engagement of Middle Managers in Civil Service Organizations: The Case of Selected federal and regional Offices in Ethiopia (PhD) A. A: ECSU.

[3] Anderson, James E. 2006. Public policymaking: an introduction (6rd edn). Boston: Houghton Mifflin Co.

[4] Atsbeha Aregawi. 2012. The Practice of Policy Making Process in Ethiopia. The case of HPR. Addis Ababa: Addis Ababa University (Master's Thesis).

[5] Bardach, E. 1977. The Implementation Game: What Happens After a Bill Becomes a Law. Cambridge: The MIT Press.

[6] Bass, B. M. 1992. Multifactor Leadership Questionnaire. Palo Aloto, CA: Consulting Psychologists Press.

[7] Barrett, S. M. 2004. "Implementation Studies: Time for a Revival? Personal Reflections on 20 Years of Implementation Studies". Public Administration 82 (2): 249-62.

[8] Bekker, J. C. O, and Heyningen, H. Van. 2011. A Strategic Leadership Model for Policy Implementation. African Journal of Public Affairs, Vol. 4, Number 1, June 2011.

[9] Berman, Paul. 1978. The Study of Macro and Micro implementation of Social Policy. The Rand Corporation, Santa Monica, California 904406.

[10] Bhola, H. S. 2004. Policy implementation: planning and actualization. Journal of Educational Planning and administration, 18 (3), 295-312.

[11] Birkland, A. Thomas 2011. An introduction to the policy process ( $3^{\text {rd }}$ edition). USA: M. E. Sharpe. INC.

[12] Biruk Shewakana. 2014. Public policymaking in Post-1991 Ethiopia: The Case of Land Lease Policy. MA Thesis, AAU.

[13] Blanchard, K. Zigarmi, P. and Zigarmi, D. 1994. Leadership and the One Minute Manager. London: Harper Collins Publishers.

[14] Bryman, A. 1992. Charisma and Leadership in Organization. London: Sage Publications.

[15] Burns, J. M. 1978. Leadership. New York: Harper \& Row.

[16] Cochran, L. Charles \& Malone, F. Eloise. 1999. Public Policy: Perspective \& Choices. USA: McGraw-Hill.

[17] Cottrell, Stella. 2005. Critical thinking skills: Developing effective analysis. Basingstoke: Palgrave Macmillan.

[18] DeLeon, Peter \& DeLeon, Linda. 2002. Whatever happened to policy implementation? An alternative approach. http:// JPart: Oxford Journal.org.

[19] Dereje Terefe. 2016. The extent of public opinion to endorse or halt public policies: A review of recent change of policy goal posts in Ethiopia. Public policy and Administration Research. Vol. 6, No. 10.
[20] Donald, S. Van M. and Carl E. V. 1975. The performancebased budgeting system: A study of poverty reduction policy implementation in Thailand.

[21] Downton, J. V. 1973. Rebel Leadership: Commitment and Charisma in Revolutionary Process. NY: Free Press.

[22] Dunn, N. William. 2004. Public Policy Analysis: An Introduction ( $3^{\text {rd }}$ ed,) Englewood Cliffs, NJ: Prentice-Hall.

[23] Dye, Thomas R. 2013. Understanding public policy $\left(13^{\text {th }}\right.$ edn.), Pearson Education, INC.

[24] Edwards, George \& Sharkansky, Ira. 1978. The policy predicament: Making and implementing public policy. USA: W. H. Freeman \& Company.

[25] Egonmwan, J. A. 1991. Public Policy An analysis: Concepts and Applications, Benin City: S. M. O. Aka and Brothers Press Focus on Citizens: Public Engagement for better policy and services. 2009. Executive Summary: OECD.

[26] Elmore, Richard F. 1979-1980. Backward-Mapping Implementation Research and Policy Decisions. Political science Quarterly, Vol. 94, No. 4, PP 601- 616 USA: Ac. Psc.

[27] Gebre Mirutse. 2015. Civil Service Reform and leadership Role in Ethiopia: The Case of Tigray Regional State. Public Policy and Administration Research. Vol. 5, No. 1.

[28] Gerston, N. L. 2010. Public policymaking: process and principles, USA: M. E. Sharp.

[29] Goggin, M. L Bowman, A. O Lester, James P. \&O'Toole. L. J. 1990. Implementation theory and practice: Toward a third generation, New York: Harper-Collins.

[30] Grindle, M. S. 1980. Politics and Policy Implementation in the Third World. NJ: Princeton University Press.

[31] Guillory, B. \& Galindo, L. Empowerment For The Performing Organizations $>$ Salt City: Innovations International Inc. Publishing Division.

[32] Habiba Siraj. 2016. The status of popular participation in public policymaking process in Ethiopia. The case of Oromia Regional State. MA. ECSU.

[33] Hargrove, E. C. 1975. The missing-link: The study of implementation of social policy. Washington Urban Institute.

[34] Heneman, III, H. G. \& Judge, T. A 2010. Staffing Organizations. Middleton: Mendota House, Inc.

[35] Hichlin, Alison and Godwin Erik. 2009. Agents of change: The role of public managers in public policy. Policy Studies journal. Volume 37, Issue 9.

[36] Hill, Michael and Hupe, Peter. 2009. Implementing Public Policy, Second edition, USA: Sage Hirschman, A. O. 1975. Policymaking and policy analysis in Latin America: A return journey. Policy Sciences, 6.

[37] Honadle, George 1979. "Implementation Analysis: The Case for an Early Dose of Realism in Development administration" in, International Development Administration: Implementation Analysis for Development, George Honadle and Rud Klauss (eds.), New York: Prager.

[38] House, R. J. 1976. A 1976 Theory of Charismatic leadership. Carbondale: University Press Howell, J. 1992. What is development policy management? DPMN Bulletin (Pilot issue): 4-5. 
[39] Ingram, H. M and Mann, D. E (eds).1980. Why policies succeed or fail. Beverly Hills: Sage.

[40] Ikechukwu, Ugwuanyi, Bartholomew \& Chukwuemeka, Emma E. O. 2013. THE OBSTACLES TO EFFECTIVE POLICY IMPLEMENTATION BY THE PUBLIC BUREAUCRACY IN DEVELOPING NATIONS: THE CASE OF NIGERIA. Kuwait Chapter of Arabian Journal of Business and Management Review Vol. 2, No. 7; March. 2013.

[41] Knill, Christoph \& Tosun, Jale. 2012. Public policy: A new introduction. UK: Palgrave Macmillan.

[42] Kouzes, J. M., \& Posner, B. Z. 2007 ( $\left.3^{\text {rd }}\right)$ Edn). 2007. The Leadership Challenge ( $4^{\text {th }}$ ed.) Sanfrancisco, CA: Jossey-Bass.

[43] LaMonte, B. 2004. Winning the NFL Way: Leadership Lessons from Football's Top Head Coaches. New York: Harper Business.

[44] Lasswell, D. Harold. 1951. "The Policy Orientation", in Policy Sciences: Recent Development in Scope and Method.

[45] Lemma Degefa. 2012. Leadership: Living and Serving. Third edition. Addis Ababa: An African Practioner's Perspective.

[46] Lester, P. James, Ann O’M Bowman, Malcolin, L, Goggin, and Laurence, J. O' Tool. 1995. Public policy implementation: Evolution of the field Agenda for Future Research, Research in public policy analysis and Management, Volume 7, pp. 71-94.

[47] Lipsky, Michael. 1980. Street-Level Bureaucracy: Dilemmas of the individual in Public Services, New York: Russel Sage Foundation.

[48] Matland, Richard E. 1995. Synthesizing the Implementation Literature. The ambiguity-conflict model of policy implementation, Journal of Public Administration Research and Theory: J-PART, Vol. 5, No. 2, pp 145-174.

[49] May, P. J. 1991. Reconsidering Policy design: Policies and Publics. Journal of public Policy, 11, (Part 2): 187-206.

[50] Maxwell, J. C. 1998. The 21 Irrefutable Laws of Leadership. Georgia; Maxwell Motivation Inc.

[51] Mazmanian, Daniel and Sabatier, Paul. 1983. Implementation and Public Policy. Glenvie:, IL Scott Foresman.

[52] Mulugeta Abebe. 2005. A Critical assessment of institutions, roles and leverage in public Policymaking in Ethiopia, 19742004 (PhD Dissertation), University of Stellenbosch (S. A).

[53] Ndah, Anthony Banyouko. 2010. Public policy and inappropriateness in Africa: Causes, Consequences and the way forward. Xiamen University: Coastal and Ocean Management Institute COMI).

[54] Nnajiofor, Og, Ifeakor Cs, and Mgbemena, S. 2004. Nigeria and the enigma of policy implementation. Volume 7, No. 2. Microsoft Word - 12. Osita.doc.

[55] Northouse, P. G. 2007. Leadership: Theory and Practice ( $4^{\text {th }}$ ed.). Thousand oaks, CA: Sage Publications, Inc.

[56] Nwagboso, Chris, I. 2012. Public Policy and the Challenges of Policy Evaluation in the Third World. British Journal of humanities and Social sciences, April 2012, Vol. 5, 91).

[57] Omer Ibrahim 2014. Policymaking practice in Ethiopia: The case of Amhara National Regional State Council. MA: ECSU.
[58] Policy Studies and Research Center. 2016. A Study Report on leadership accountability in selected public institutions: Addis Ababa.

[59] Pollitt, C. 2003. The essential public manager. Mc-Graw-Hill Education (UK).

[60] Pressman, J. and Wildavsky, A. 1973. Implementation: How Great Expectations in Washington Are dashed in Oakland: or, Why it is Amazing that the federal Programs Work All, Charless Cole, III Book Review.

[61] Rein, M \& Rabinowtz F. F. 1978. Implementation: a theoretical perspective, in Burnham, W. D. and Weinberg. M. W. American Politics and Public Policy. Cambridge, MA: MIT.

[62] Robichau, Waters, L. and Laurence, E. 2009. The Implementation of public policy: Still the Missing link. Policy Studies Journal, (37) 1.

[63] Sabatier, Paul and Mazmaiman Daniel. 1980. The Implementation of Public Policy: A Framework of Analysis. Policy Studies journal, 8 (2): 538-560.

[64] Scheberle, Denise. 1997. Federalism \& Environmental Policy: Trust and politics of implementation (American Governance and Public Policy Series).

[65] Schofield, Jill 2004. Time for a revival? Public policy implementation: a review of the literature and an agenda for future research,. International Journal of Management Review, Volume 3, Issue 3, pp. 245-263.

[66] Signe, Landry. 2017. Public service delivery- What matters for successful implementation and can policy leaders do? $O C P$ Policy Center.

[67] Stogdill, R. M. 1974. Handbook of Leadership. A survey of theory and research. NY: Macmillan Publishers Co. Inc.

[68] Surel, Y. 2000. The role of cognitive and normative frames in policymaking. Journal of European Public Policy, 7 (4), 495512.

[69] Taye Assefa (ed.). 2010. Digest of Ethiopia's National Policies, Strategies and Programs. Addis Ababa: Forum for Social Studies.

[70] Tiruye Alemu and Dereje Terefe. 2018. Assessment of the cause of policy-implementation dichotomy narratives in Ethiopia: The case of selected public institutions. Public policy and Administration.

[71] Van Meter, Donald S. and Van Carl E. Horn. 1975. "The Policy Implementation Process: A Conceptual Framework". Administration and Society, 6: 445-488.

[72] Weber, M. 1947. The Theory of Social and Economic Organization. New York; Free Press Wildavsky, Aaron. 1975. If planning is everything, maybe it's nothing. In A. P Johnston \& J. F. McNamara (Eds.), Planning Perspectives for Education (pp 267-287). New York: MSS.

[73] Weaver, Kent. R. 2009. But what will work? Implementation analysis to improve government performance. Governance Studies at BROOKINGS: Issues in Governance Studies (Numberb32/2020).

[74] Wildavsky, Aaron. 1975. If planning is everything, maybe it's nothing. In A. P Johnston \& J. F. McNamara (Eds.), Planning Perspectives for Education (pp 267-287). New York: MSS Information Corporation. 
[75] Winter, Soren. 1990. 'Integrating Implementation research', in Dennis J. Plambo and Donald J. Calista (eds), Implementation and the policy process, Opening Up the Black Box, Westport, CT: Greenwood Press, Pp. 19-38.

[76] Wu, Xin, Ramesh. M., Howlett, M., and Fritzen, Scott. 2010. The public Policy Primer: Managing the policy process, London: Routledge.
[77] Yukul, G. A. 2010. Leadership in Organizations. New Jersey: Prentice hall.

[78] Zerihun Deressa and Tesfaye Debela. 2014. Leadership Effectiveness in Public Service Organizations of Ethiopia: Perception of Leaders in public service organizations. Journal of Law and Globalization, Vol. 26. 